Supporting Information

\title{
Multifarious Chiral Nanoarchitectures Serving as Handed-Selective Fluorescence Filters for Generating Full-Color Circularly Polarized Luminescence
}

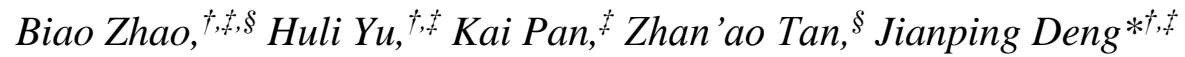

${ }^{\dagger}$ State Key Laboratory of Chemical Resource Engineering, Beijing University of Chemical Technology, Beijing 100029, China

*College of Materials Science and Engineering, Beijing University of Chemical

Technology, Beijing 100029, China

${ }^{\S}$ Beijing Advanced Innovation Center for Soft Matter Science and Engineering, State

Key Laboratory of Organic-Inorganic Composites, Beijing University of Chemical

Technology, Beijing 100029, China

*E-mail: dengjp@mail.buct.edu.cn 


\section{Contents}

Figure S1. Schematic illustration for preparing chiral polymer nanofibers .............................3

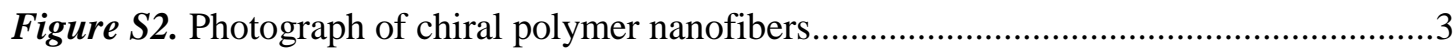

Figure S3. Photograph of chiral composite films ….............................................................

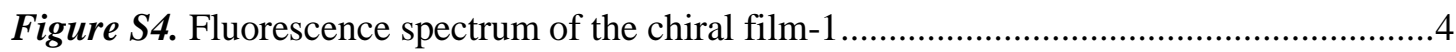

Figure S5. CD spectra of achiral dye-1 based fluorescent film ...............................................

Figure S6. CPL spectra of achiral dye-1 based fluorescent film .............................................5

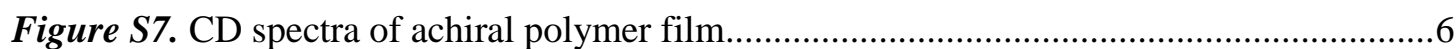

Figure S8. The obtained CPL spectra by combining achiral polymer film with dye-1 fluorescent film.

Figure S9. The obtained CPL spectra when reversing the relative position of chiral film and fluorescent film.

Figure S10. The obtained CPL spectra with high content of chiral polymer nanofibers...........7

Figure S11. The obtained CPL spectra when dissolving dye-1 into chiral polymer nanofiber dispersion.

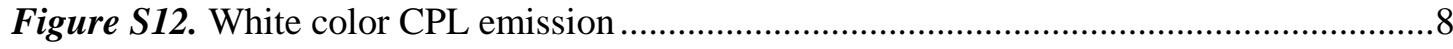

Figure S13. Polarized optical micrograph of chiral film-3 ....................................................

Figure S14. Photograph illustration for preparing chiral $\mathrm{CuO} @ \mathrm{CNC}$ nanoflowers...................

Figure S15. FT-IR spectrum of $\mathrm{CuO} @ \mathrm{CNC}$ nanoflowers ........................................................

Figure S16. Fluorescence spectrum of $\mathrm{CuO} @ \mathrm{CNC}$ nanoflowers ............................................10

Figure S17. The obtained CPL spectra when reversing the relative position of chiral $\mathrm{CuO} @ \mathrm{CNC}$ nanoflowers and fluorescent dyes during the test process.

Figure S18. CD and UV-vis spectra of chiral CNC dispersion (contains $0.02 \mathrm{wt} \% \mathrm{CNC}$ ). 11

Figure S19. CPL spectra derived from chiral CNC dispersion and achiral fluorescent dyes excited at $320 \mathrm{~nm}$.

Figure S20. FT-IR spectrum of calcined $\mathrm{CuO}$ nanoflowers..................................................12

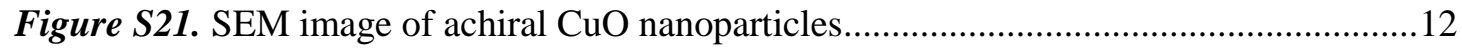

Figure S22. CD and UV-vis spectra of achiral $\mathrm{CuO}$ nanoparticles ......................................13

Figure S23. CPL spectra derived from achiral $\mathrm{CuO}$ nanoparticles and achiral fluorescent dyes excited at $320 \mathrm{~nm}$ 


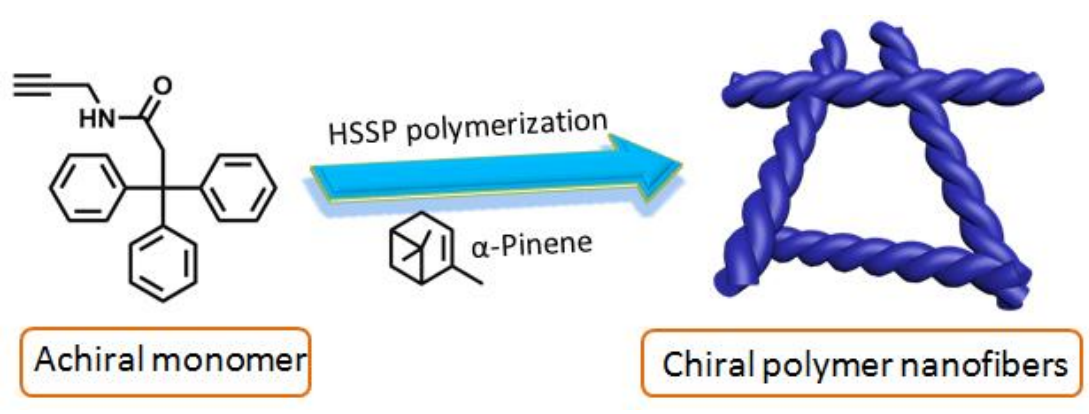

Figure S1. Schematic illustration for preparing chiral polymer nanofibers by HSSP of chiral substituted acetylenic monomer.

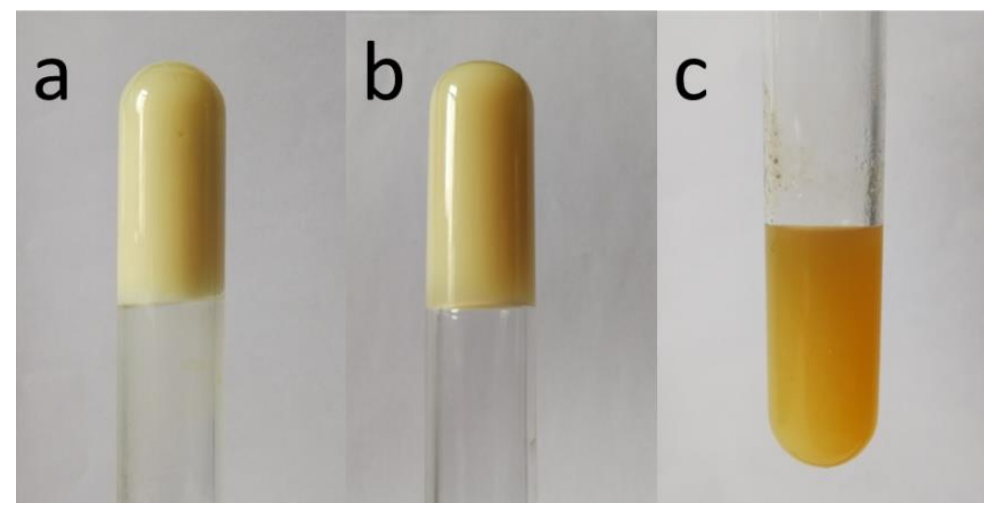

Figure S2. Photograph of chiral polymer nanofibers prepared by HSSP at varied solvent ratios: (a) $\mathrm{CHCl}_{3} / \alpha$-pinene $=6 / 0(\mathrm{v} / \mathrm{v}) ;$ (b) $\mathrm{CHCl}_{3} / S$ - $\alpha$-pinene $=4 / 2(\mathrm{v} / \mathrm{v}) ;$ (c) $\mathrm{CHCl}_{3} / R$ - $\alpha$-pinene $=4 / 2(\mathrm{v} / \mathrm{v})$. The monomer concentration was kept at $0.05 \mathrm{~mol} / \mathrm{L}$ in all the samples.

When achiral monomer underwent polymerization in pure $\mathrm{CHCl}_{3}$ without $\alpha$-pinene, visible polymer physical gel was formed. When chiral $\alpha$-pinene was employed to the HSSP process, the polymerization phenomena were slightly different. For $S$ - $\alpha$-pinene, polymer gel could be also formed but more reaction time was needed. For $R$ - $\alpha$-pinene, only gel-like solution was obtained. This can be explained by the role of $\alpha$-pinene, which acts as a poor solvent during the polymerization process and consequently prevents the formation of regular polymer gels. ${ }^{1}$ 


$\begin{array}{clllll}\text { BUCT } & \text { BUCT } & \text { BUCT } & \text { BUCT } & \text { BUCT } & \text { BUCT } \\ \text { BUCT } & { }^{\text {BUCT }} & \text { BUCT } & \text { BUCT } & \text { BUCT } & \text { BUCT } \\ \text { BUCT } & \text { BUCT } & \text { BUCT } & \text { BUCT } & \text { BUCT } & \text { BUCT } \\ \text { BUCT } & \text { BUCT } & \text { BUCT } & \text { BUCT } & \text { BUCT } & \text { BUCT } \\ \text { BUCT } & \text { BUCT } & \text { BUCT } & \text { BUCT } & \text { BUCT } & \text { BUCT } \\ \text { BUCT } & \text { BUCT } & \text { BUCT } & \text { BUCT } & \text { BUCT } & \text { BUCT } \\ \text { BUCT } & \text { BUCT } & \text { BUCT } & \text { BUCT } & \text { BUCT } & \text { BUCT }\end{array}$

Figure S3. Photograph of the chiral composite films: (a) film-1; (b) film-2 and (c) film-3.

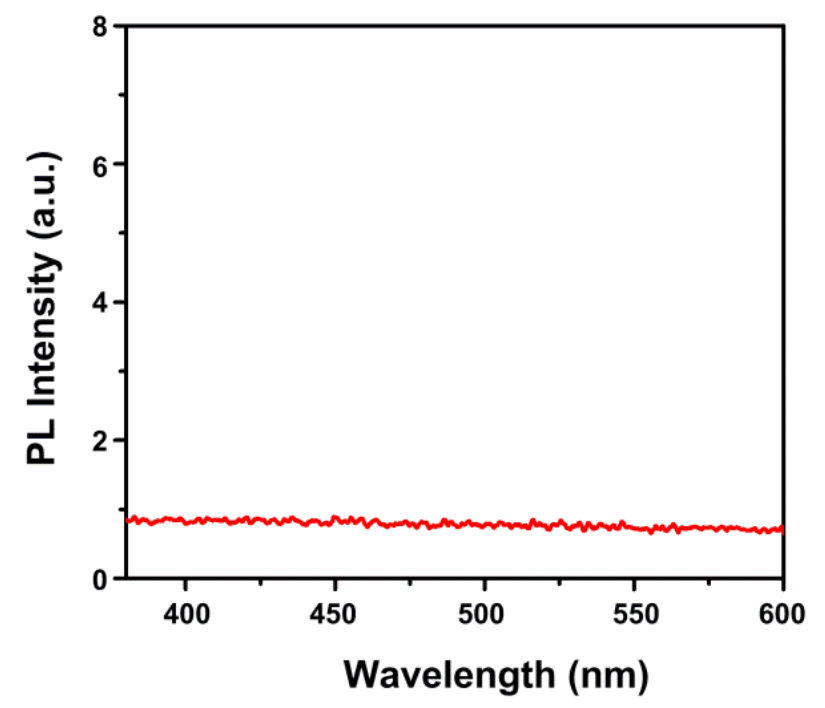

Figure S4. Fluorescence spectrum of chiral film-1 $\left(\lambda_{\mathrm{ex}}=365 \mathrm{~nm}\right)$. 


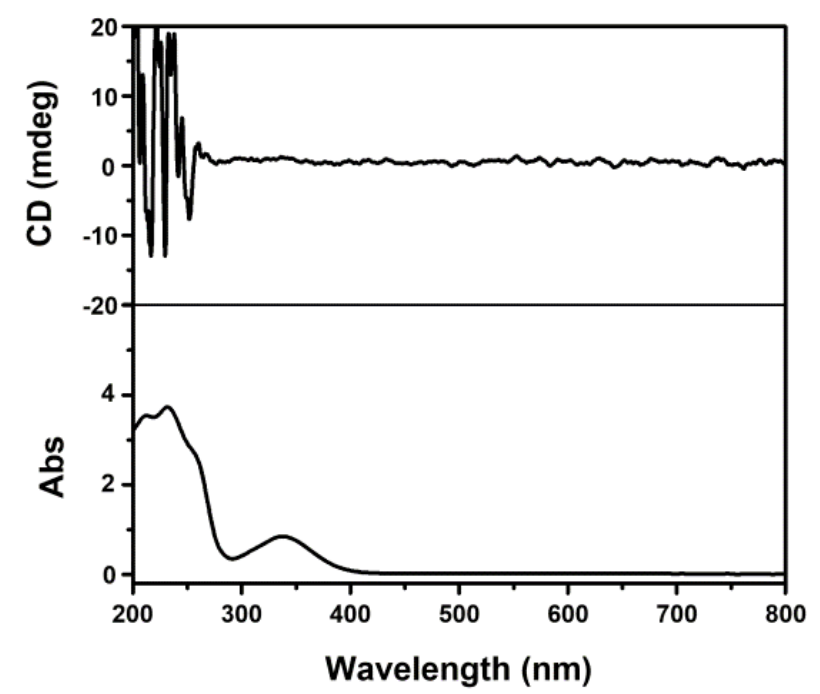

Figure S5. CD spectra of achiral dye-1 based fluorescent film.

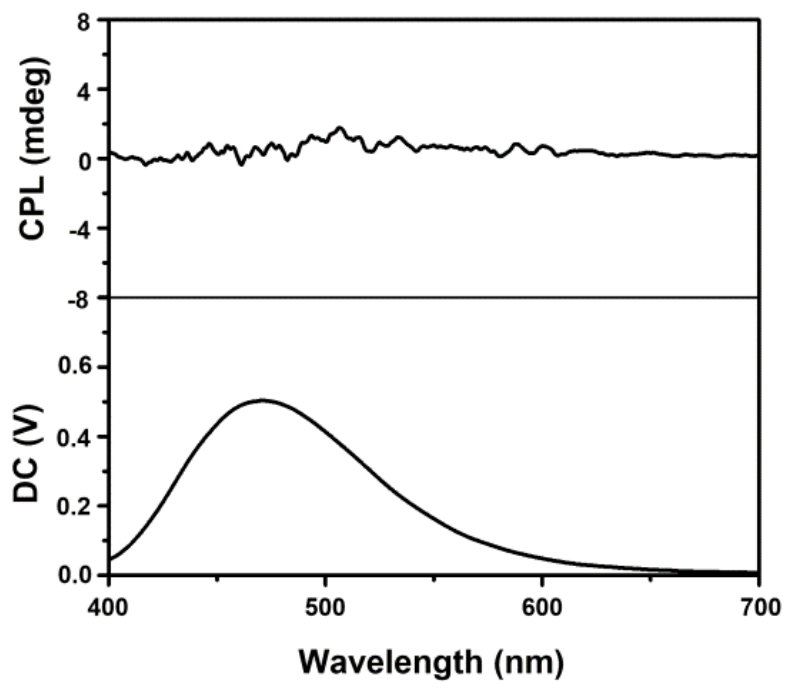

Figure S6. CPL spectra of achiral dye-1 based fluorescent film. 


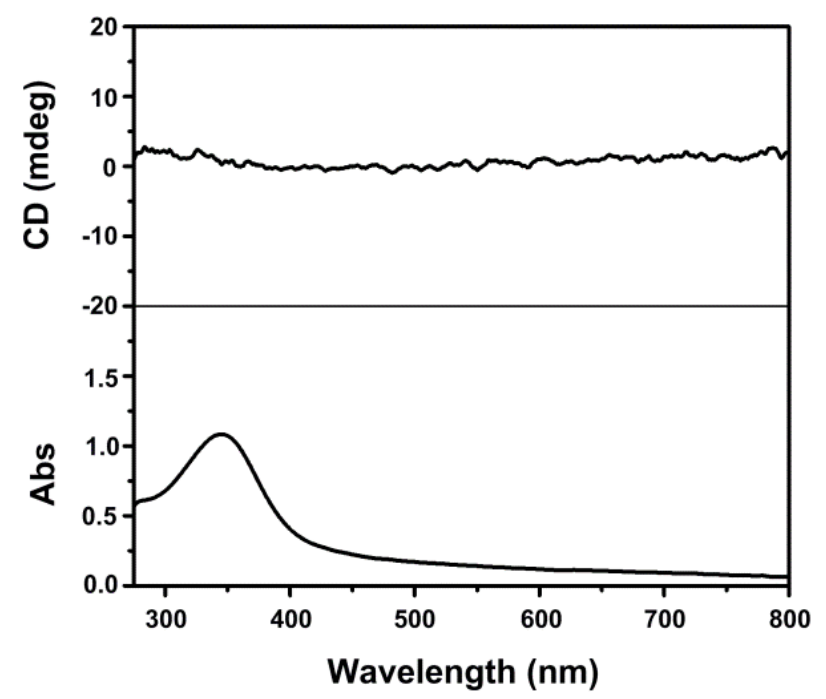

Figure S7. CD spectra of achiral polymer film. The film was prepared by dispersing racemic polymer nanofibers (the sample in Figure 1a) in PMMA solution.

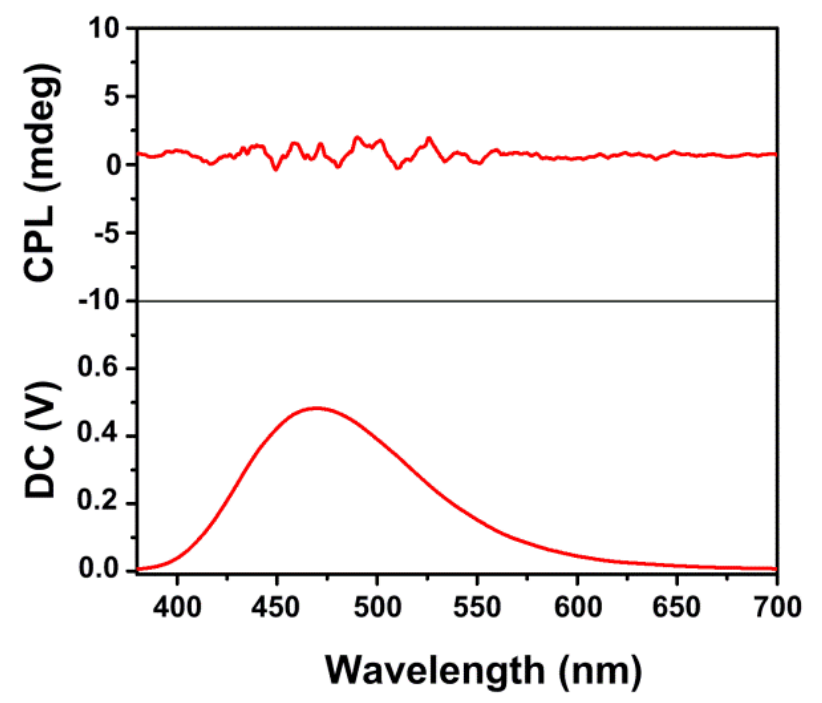

Figure S8. The obtained CPL spectra by combining achiral polymer film with dye-1 fluorescent film. 


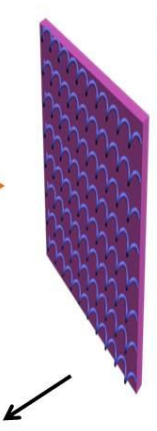

Chiral film

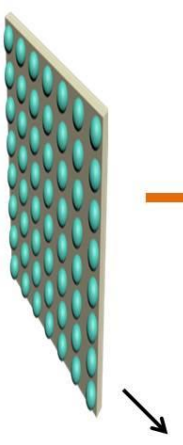

Achiral fluorescent film

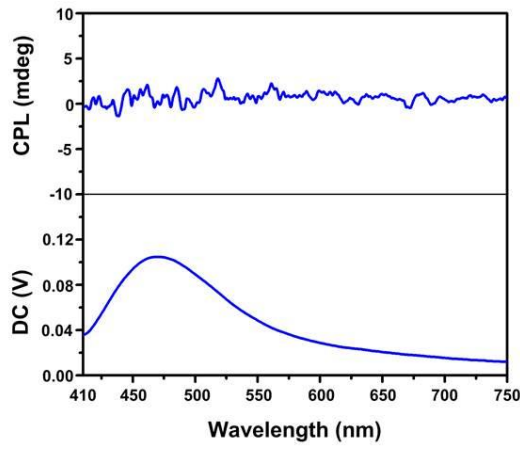

CPL-silent

Figure S9. The obtained CPL spectra when reversing the relative position of chiral film and fluorescent film. No CPL signal is found in this case.

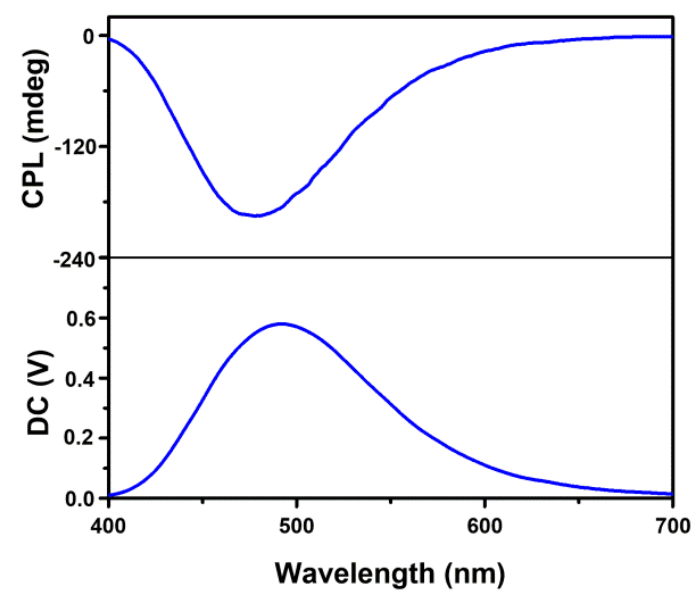

Figure S10. The obtained CPL spectra with high content of chiral polymer nanofibers.

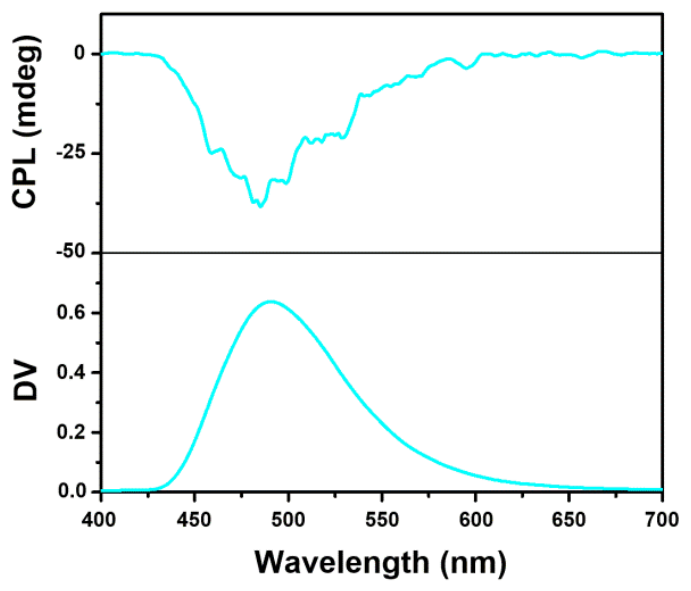

Figure S11. The obtained CPL spectra when dissolving dye-1 into chiral polymer nanofiber dispersion. 

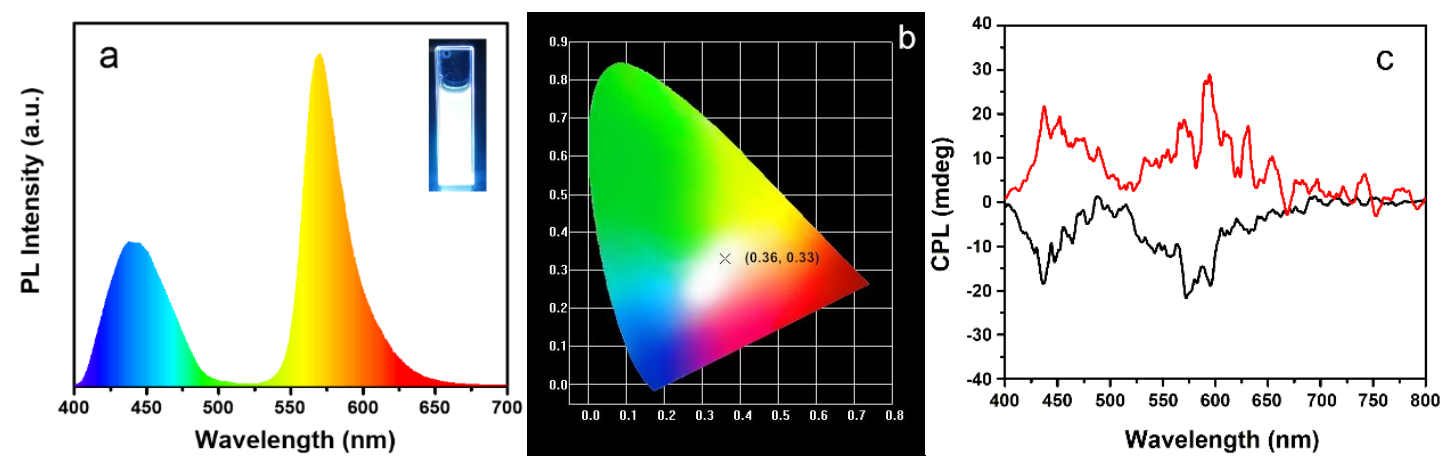

Figure S12. (a) Fluorescence spectra of the white-color chiral dispersions. Inset: Photograph of the chiral dispersions under UV-365 irradiation. (b) The $1931 \mathrm{CIE}$ coordinate diagram and (c) CPL spectra of the white-color chiral dispersions.

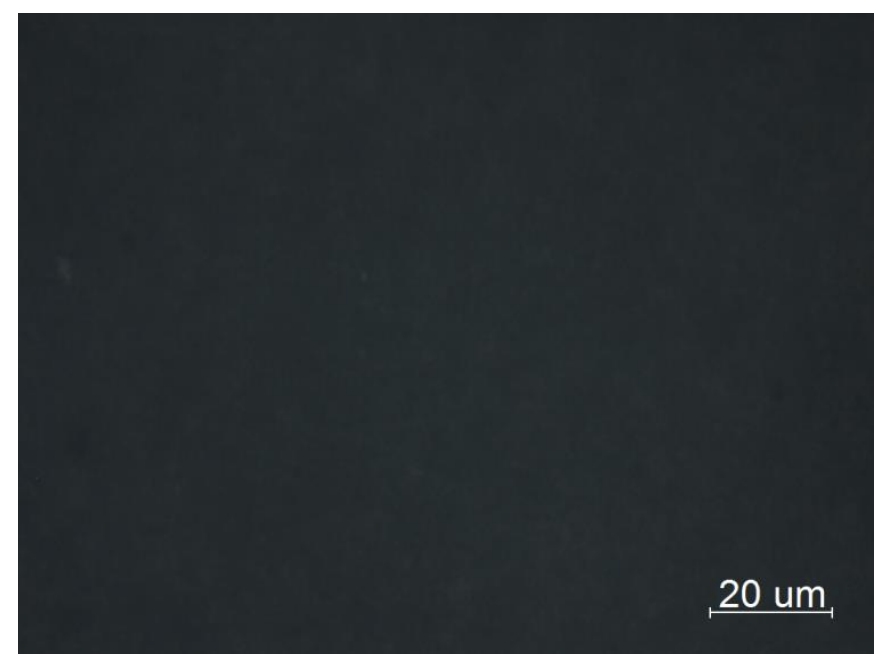

Figure S13. Polarized optical micrograph of chiral film-3. 


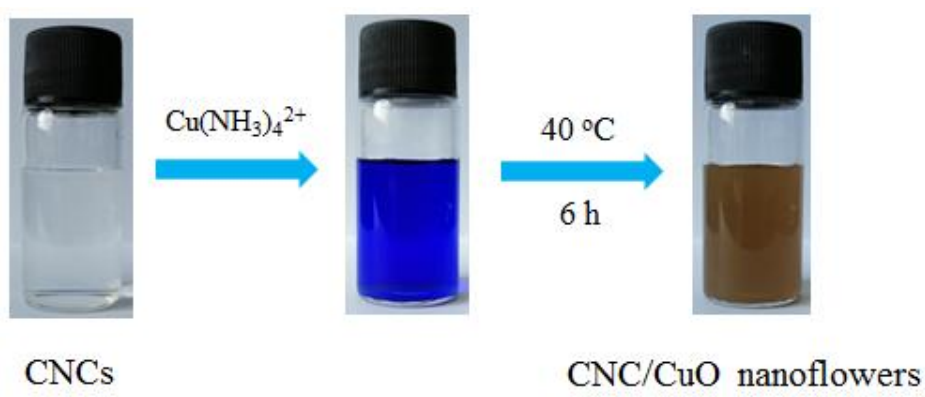

Figure S14. Photograph illustration for preparing chiral $\mathrm{CuO} @ \mathrm{CNC}$ nanoflowers.

The strategy for preparing chiral $\mathrm{CuO} @ \mathrm{CNC}$ nanoflowers consisted of two major steps in one pot: cellulose- $\mathrm{Cu}\left(\mathrm{NH}_{3}\right)_{4}{ }^{2+}$ complexes were firstly formed by coordinating $\mathrm{Cu}\left(\mathrm{NH}_{3}\right)_{4}{ }^{2+}$ irons with $-\mathrm{OH}$ groups on the surface of $\mathrm{CNCs}$, and the complexes served as nucleation sites for the subsequent in situ formation of $\mathrm{Cu}(\mathrm{OH})_{2}$. In the second step, $\mathrm{CuO}$ nanofibers were formed with ammonia evaporation by heating. The $\mathrm{CuO}$ nanofibers further grew along the surface of $\mathrm{CNC}$ nanorod, yielding the chiral $\mathrm{CuO} @ \mathrm{CNC}$ nanoflowers. Meanwhile, the color of complexs transformed form dark blue to yellowish-brown after the formation of $\mathrm{CuO} @ \mathrm{CNC}$ nanoflowers.

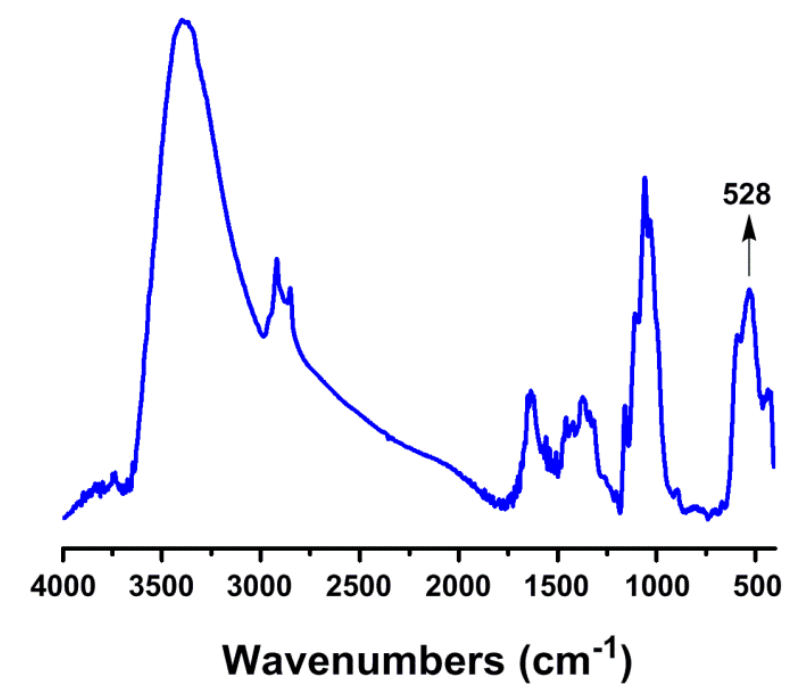

Figure S15. FT-IR spectrum of $\mathrm{CuO} @ \mathrm{CNC}$ nanoflowers. 


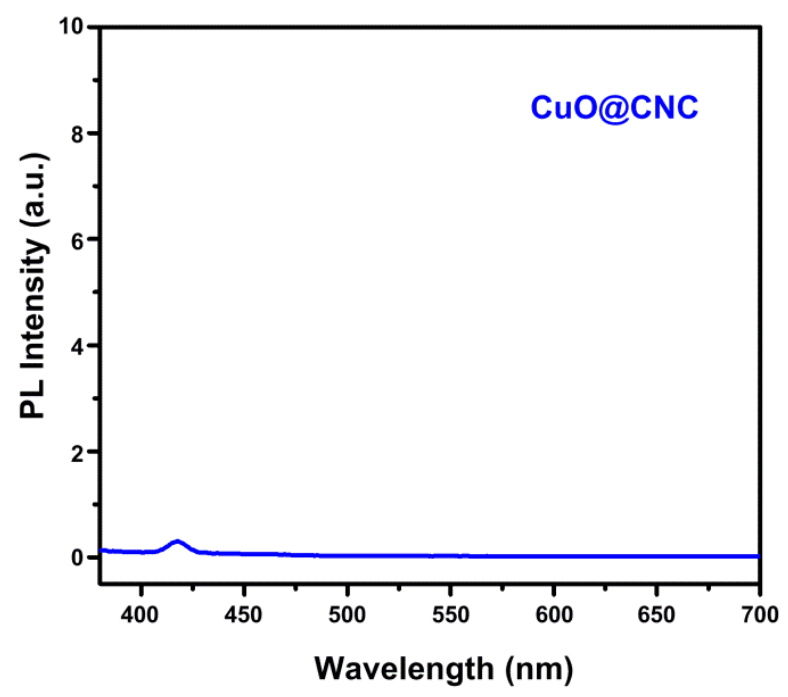

Figure S16. Fluorescence spectrum of $\mathrm{CuO} @ \mathrm{CNC}$ nanoflowers $\left(\lambda_{\mathrm{ex}}=365 \mathrm{~nm}\right)$.

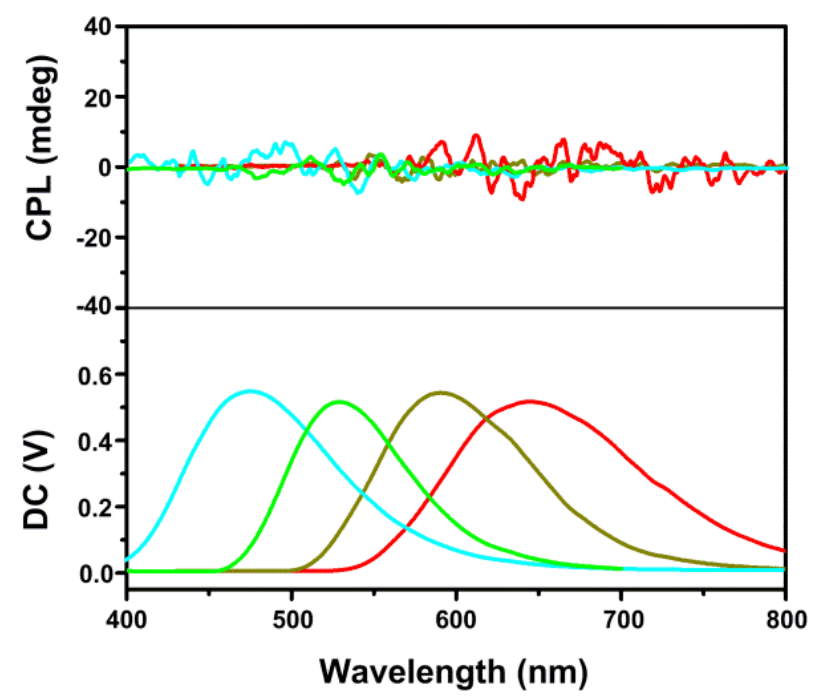

Figure S17. The obtained CPL spectra when reversing the relative position of chiral $\mathrm{CuO} @ \mathrm{CNC}$ nanoflowers and fluorescent dyes during the test process. 

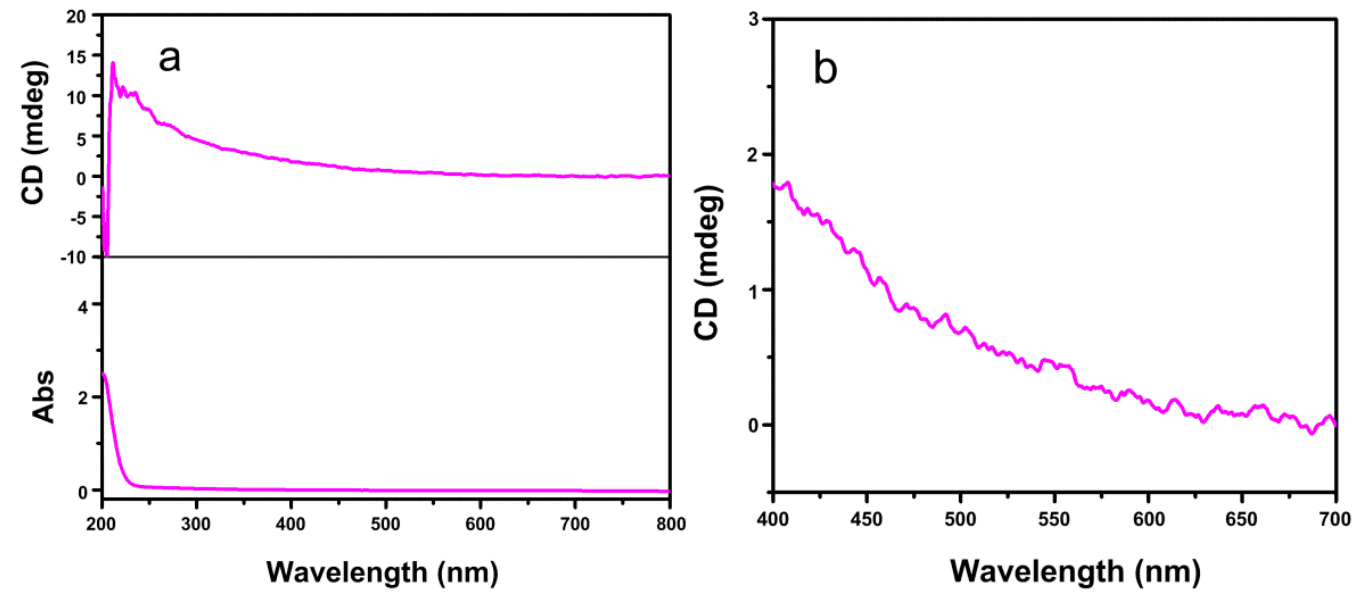

Figure S18. (a) CD and UV-vis spectra of chiral CNC dispersion (contains $0.02 \mathrm{wt} \%$ CNC). (b) The partially magnified CD spectra.

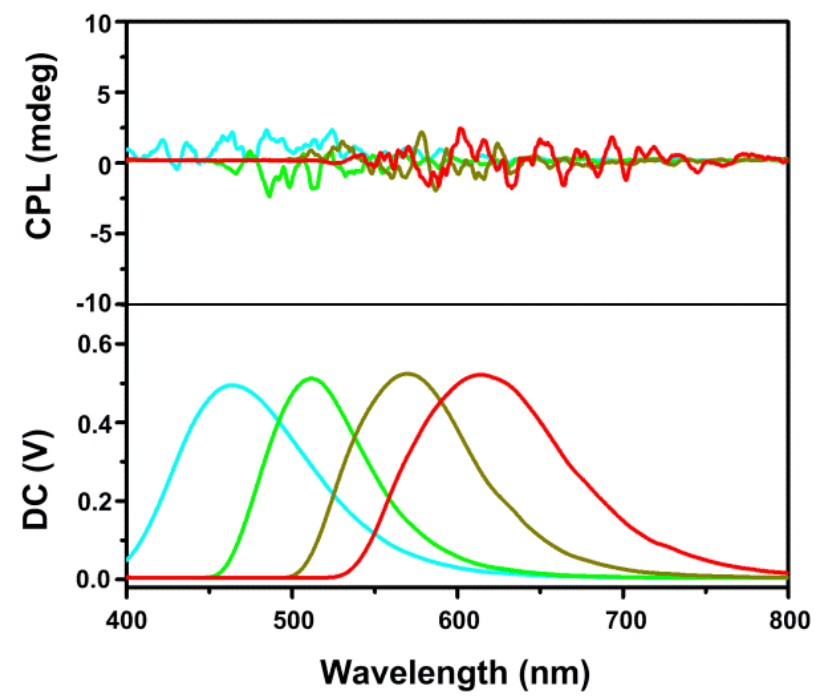

Figure S19. CPL spectra derived from chiral CNC dispersion and achiral fluorescent dyes excited at $320 \mathrm{~nm}$. 


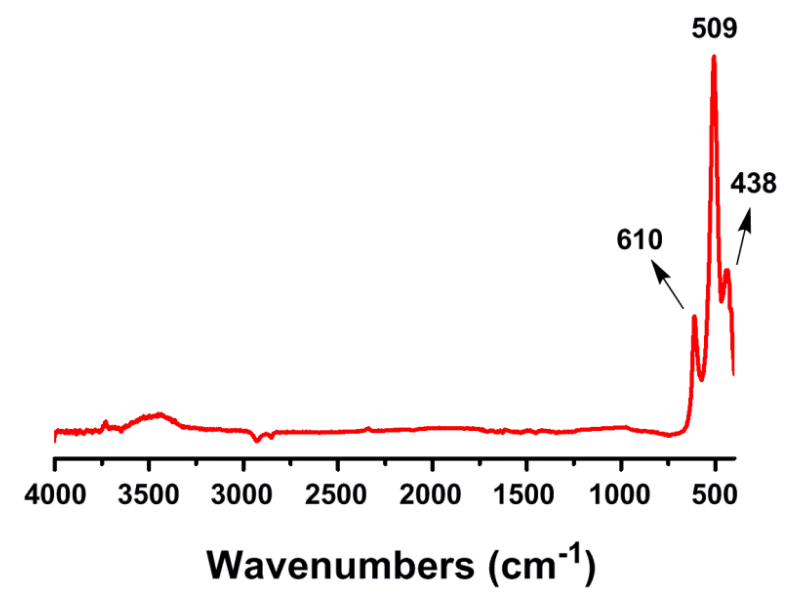

Figure S20. FT-IR spectrum of calcined $\mathrm{CuO}$ nanoflowers. The peaks at 438, 509 and $610 \mathrm{~cm}^{-1}$ are assigned to the $\mathrm{Au}$ mode, $\mathrm{Bu}$ mode, and another $\mathrm{Bu}$ mode, respectively. ${ }^{2,3}$

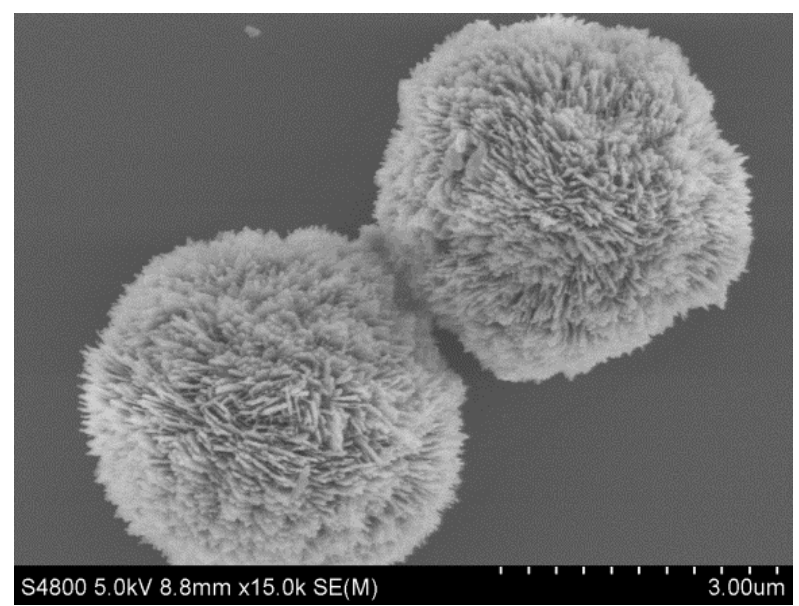

Figure S21. SEM image of achiral $\mathrm{CuO}$ nanoparticles. 


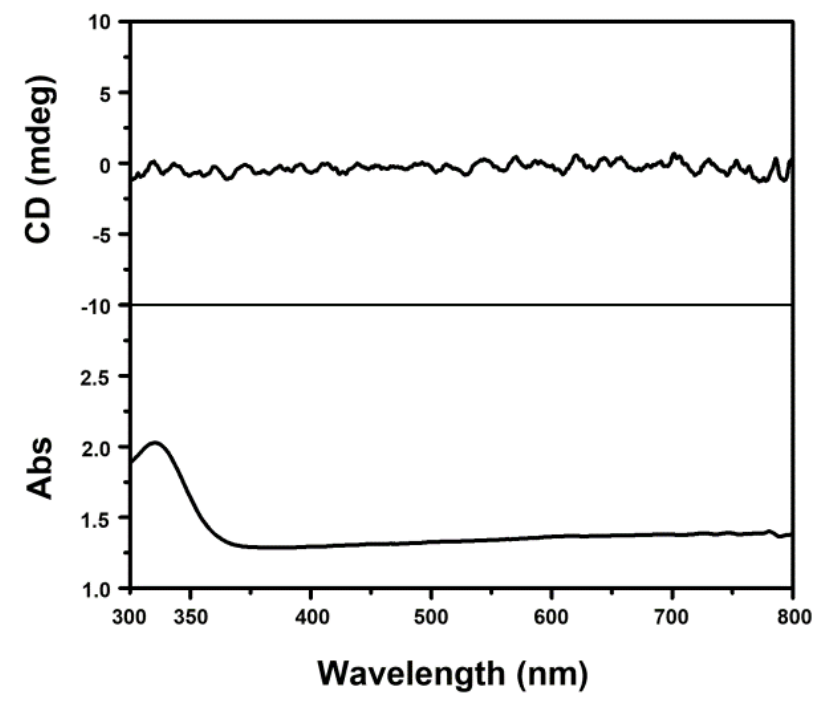

Figure S22. $\mathrm{CD}$ and $\mathrm{UV}$-vis spectra of achiral $\mathrm{CuO}$ nanoparticles.

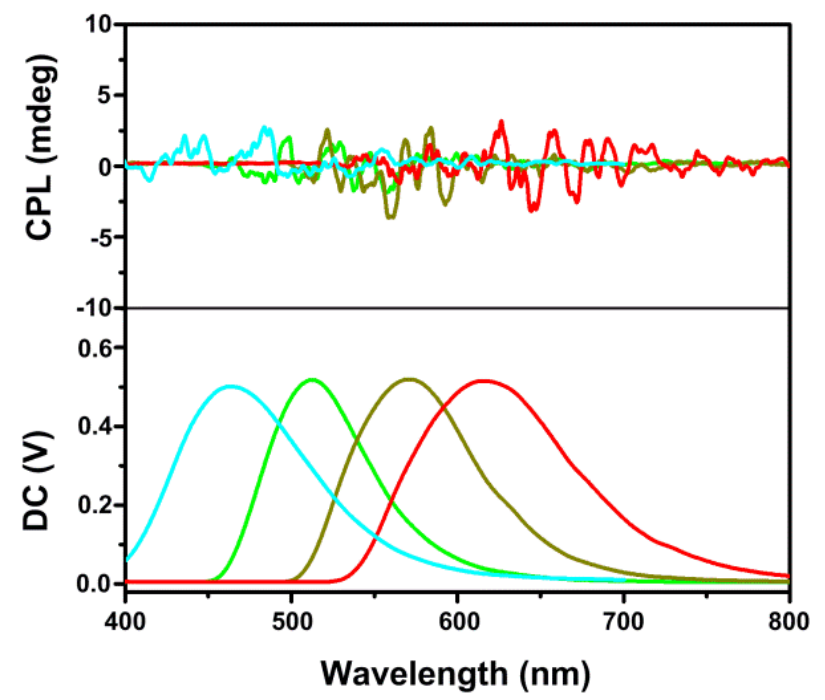

Figure S23. CPL spectra derived from achiral $\mathrm{CuO}$ nanoparticles and achiral fluorescent dyes excited at $320 \mathrm{~nm}$. 


\section{References}

(1) Zhang, Y.; Deng, J.; Pan, K. Chiral Helical Polymer Nanomaterials with Tunable Morphology: Prepared with Chiral Solvent to Induce Helix-Sense-Selective Precipitation Polymerization. Macromolecules 2018, 51, 8878-8886.

(2) Kliche, K.; Popovic, Z. V. Far-Infrared Spectroscopic Investigations on CuO. Phys. Rev. $B$ 1990, 42, 10060-10066.

(3) Zou, G.; Li, H.; Zhang, D.; Xiong, K.; Dong, C.; Qian, Y. Well-Aligned Arrays of CuO Nanoplatelets. J. Phys. Chem. B 2006, 110, 1632-1637. 